\title{
Prevalence of and risk factors associated with Cryptosporidium infection in an underdeveloped rural community of southwest China
}

Ya Yang ${ }^{1,2,3}$, Yi-Biao Zhou ${ }^{1,2,3^{*}}$, Peng-Lei Xiao ${ }^{1,2,3}$, Yan Shi ${ }^{1,2,3}$, Yue Chen ${ }^{4}$, Song Liang ${ }^{5,6}$, Wu-Li Yihuo ${ }^{7}$, Xiu-Xia Song ${ }^{1,2,3}$ and Qing-Wu Jiang ${ }^{1,2,3}$

\begin{abstract}
Background: Cryptosporidium spp. is an important intestinal protozoan causing diarrhea in humans, livestock, and wild animals. Cryptosporidium infection remains a major public health issue, but its epidemiology in humans is still unclear, particularly in rural China. This study was designed to determine the prevalence of and risk factors associated with Cryptosporidium infection in a rural southwestern Chinese community.

Methods: A community-based cross-sectional survey was conducted among 687 residents of a small town in a Yi autonomous prefecture of southwest China in 2014. Blood samples were examined using a broad set of quality-controlled diagnostic methods for hepatitis B virus (HBV) and human immunodeficiency virus (HIV). Stool specimens were processed using the modified acid-fast staining method, and microscopically examined for Cryptosporidium infection. Univariable and multivariable analyses were performed to determine the risk factors associated with Cryptosporidium infection.

Results: The majority of the participants were Yi people with poor living conditions and unsatisfactory hygiene habits, and the study area was of very low socioeconomic status. Of the 615 individuals included in the analysis, 14 (2.3\%) were HIV positive, 51 (8.3\%) were infected with HBV, and 74 (12.0\%) had Cryptosporidium infection. The prevalences of HIV/HBV, HIV/Cryptosporidium, and HBV/Cryptosporidium co-infections were $0.3 \%, 0.3 \%$, and $1.8 \%$, respectively. The prevalence of HBV infection was higher in individuals with Cryptosporidium infection $\left(X^{2}=5.00\right.$, $P=0.03)$. Owning livestock or poultry was an important risk factor for Cryptosporidium infection $(a O R=2.27,95 \% \mathrm{Cl}$ : $1.01-5.08, P<0.05)$. Cryptosporidium infection was significantly associated with HBV infection $(a O R=3.42,95 \% \mathrm{Cl}$ : 1.47-7.92, $P<0.01)$, but not with HIV infection ( $\mathrm{aOR}=0.57,95 \% \mathrm{Cl}: 0.07-4.39, P=0.59)$.

Conclusions: The prevalence of Cryptosporidium infection was high in the rural area of southwestern China that was investigated, and there was a significant association between HBV infection and Cryptosporidium infection. Further investigations are needed to determine the significance of Cryptosporidium infection in patients infected with HBV.
\end{abstract}

Keywords: Cryptosporidium, Hepatitis B virus, Human immunodeficiency virus, Prevalence, Risk factors, Rural areas, China

\footnotetext{
* Correspondence: z_yibiao@hotmail.com

${ }^{1}$ School of Public Health, Fudan University, Building 8, 130 Dong'an Road, Xuhui District, Shanghai 200032, China

${ }^{2}$ Key Laboratory of Public Health Safety, Fudan University, Ministry of

Education, Building 8, 130 Dong'an Road, Xuhui District, Shanghai 200032,

China

Full list of author information is available at the end of the article
} 


\section{Multilingual abstracts}

Please see Additional file 1 for translations of the abstract into the five official working languages of the United Nations.

\section{Background}

Cryptosporidium is an important protozoan parasite, which causes diarrheal disease in humans worldwide [1]. The Global Enteric Multicenter Study assessed the causes, burden, clinical syndromes, and adverse outcomes of moderate-to-severe diarrhea involving more than 20000 children in Sub-Saharan Africa and South Asia, and found that Cryptosporidium was second only to rotavirus as a cause of moderate-to-severe diarrhea in children younger than 2 years [2]. Although Cryptosporidium was first discovered in 1907, it was not until 1976 that this parasite was identified as a cause of human infection [3]. In 2004, cryptosporidiosis was added to the World Health Organization's 'Neglected Diseases Initiative', which includes diseases affecting people mainly in low-resource settings [4].

In immunocompetent individuals, Cryptosporidium infection may be asymptomatic or cause self-limiting diarrhea. In immunocompromised patients such as those with human immunodeficiency virus (HIV)/acquired immune deficiency syndrome (AIDS), however, Cryptosporidium may cause severe, chronic, and possibly lifethreatening diarrhea, and profound malnutrition or wasting. Despite the relative consensus of opinion regarding the severity of Cryptosporidium infection in patients with HIV/AIDS, there does not seem to be a shared understanding of the risks for other groups of immunosuppressed individuals, including those with hepatitis B virus (HBV) infection. There is mounting evidence indicating that the immune system is compromised in patients with HBV [5]. However, data on the epidemiology of Cryptosporidium infection in individuals infected with $\mathrm{HBV}$ is scarce.

Numerous studies have demonstrated the critical importance of cryptosporidiosis, but Cryptosporidium failed to convince the pharmaceutical industry that a market for new therapeutics exists. Consequently, there is no specific therapeutic agent available. In the absence of effective specific treatment and a lack of access to health care, Cryptosporidium continues to be a major cause of opportunistic infections in developing countries.

In China, the first human cases of cryptosporidiosis were reported in 1987 in Nanjing, Jiangsu Province [6]. Since then, increasing attention has been paid to Cryptosporidium, and a number of epidemiological investigations have confirmed the existence of human cryptosporidiosis in at least 14 out of the 32 provinces in China [7]. However, previous studies have focused on children or patients with diarrhea or HIV/AIDS [7, 8], and few studies were designed to investigate the overall prevalence and epidemiology of cryptosporidiosis of the general population in rural areas, and none have been conducted among people other than the Han nationality $[7,9]$.

We conducted a cross-sectional study in an underdeveloped region inhabited by the Yi people, an ethnic minority group in P.R. China, with a high prevalence of HIV/AIDS and HBV [10, 11]. Local farmers in this community are engaged in mixed agricultural practices and use animal manure and human excreta as important organic fertilizers. People have close and frequent contact with domestic animals, and there is a lack of access to sanitation facilities. The primary aim of this research was to determine the prevalence of Cryptosporidium infection, and its association with HIV and HBV and other risk factors in the region.

\section{Methods}

Study area and participants

This community-based cross-sectional study was carried out in M town, P County of a Yi autonomous prefecture, southwest China. This town covers about $50 \mathrm{~km}^{2}$, with a population of approximately 4000 , and has a complex topography with mountains and valleys at an elevation of 1800 to $2500 \mathrm{~m} \mathrm{[12]}$. The main rainy season is from May to October, although occasional rain occurs at all times of the year. According to meteorological statistics, the average temperature for the region is about $16.8{ }^{\circ} \mathrm{C}$ and the average rainfall is about $1170 \mathrm{~mm}$ per year. Winters feature mild days and cool nights, whilst summers are very warm and humid.

The residents are engaged in husbandry, and produce food crops such as corn, potato, oats, and vegetables. Domestic animals outnumber humans in the area. Agriculture and animal husbandry employ more than $90 \%$ of the population. It was not until 2006 that lavatories, latrines, or any other forms of sanitation facilities became available. Until then, both human and domestic animal feces were left undisposed [12].

Participants who had lived in the area for over 6 months were invited to participate in the study. Participants who had severe organic or mental diseases and pregnant women were excluded. A total of 687 individuals were randomly selected from four villages (named A, B, C, and D, as shown in Fig. 1).

\section{Study procedures}

The study was carried out from 23rd October until 3rd November 2014. After a brief introduction of the study at the site, each of the participants from the study villages was registered and given a clean plastic container for collecting a single stool sample of at least $30 \mathrm{~g}$ in the morning at home. Specific instructions were given for proper collection and avoidance of possible contamination. A structured questionnaire was administered to 


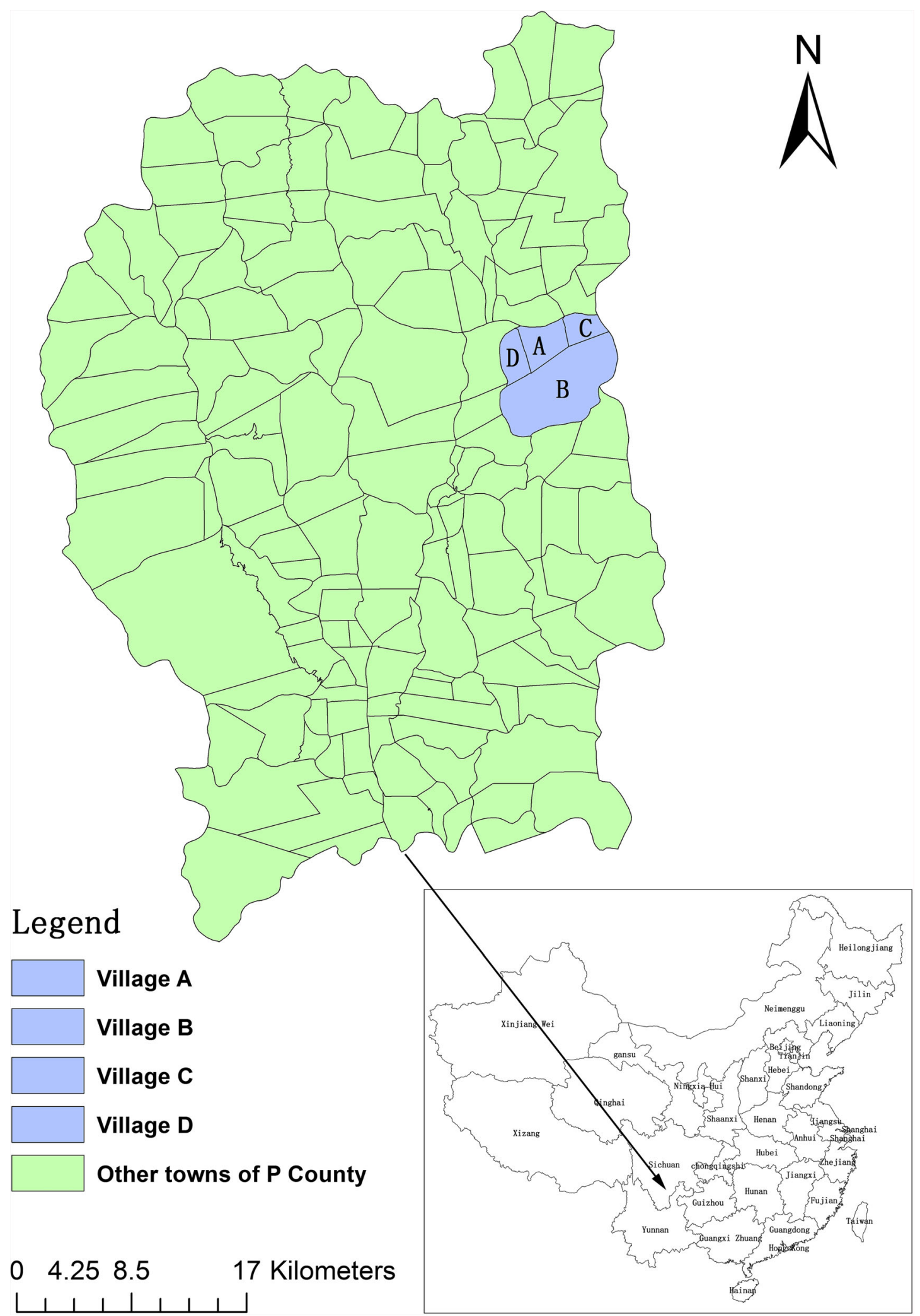

Fig. 1 Administrative map of study area (P County of a Yi autonomous prefecture, southwest China). M town consists of four villages named A, B, C, and D 
each participant by fieldworkers from the local Center for Disease Control and Prevention (CDC) to gather information about sociodemographic characteristics (including name, age, gender, ethnicity, marital status, education, occupation, annual family income and keeping livestock or poultry), personal hygiene habits (including drinkng unboiled water, washing hands before meals and after defecation and washing before eating raw fruits and raw vegetables) and access to safe water and sanitation facilities.

All the participants had a finger prick to obtain about $1 \mathrm{ml}$ of blood and were screened for HBV surface antigen and anti-HIV antibodies in the field using the diagnostic test kit for HBV (colloidal gold) (Livzon Pharmaceutical Group Inc., Zhuhai, P. R. China) and the diagnostic test kit for HIV (colloidal gold) (Xiamen Interactive Technology Co., Ltd., Xiamen, P. R. China). Positive individuals were asked to provide $5 \mathrm{ml}$ blood specimen for conformation. These blood samples were stored in the $\mathrm{CDC}$ laboratory refrigerator, which was kept at a constant temperature of $-20{ }^{\circ} \mathrm{C}$. Conformation tests were conducted by using the diagnostic kits for quantification of HBV DNA and HIV-1 RNA (polymerase chain reaction fluorescence probe method) (DAAN Gene Group Inc., Zhongshan, P. R. China) at the Center for Tropical Disease Research, Fudan University.

Stool samples were collected once for each participant and sent to the laboratory of the local CDC as soon as possible. All the specimens were processed on the day of collection, using modified acid-fast staining. Thin smears were prepared from freshly collected stool samples, and were air dried before fixation ( $5 \mathrm{~s}$ on a candle flame). The smears were stained with carbol fuchsin for $10 \mathrm{~min}$ and thereafter washed with tap water. The slides were decolorized with 3\% acid alcohol for 2 min and were counterstained with methylene blue for another $30 \mathrm{~s}$ and dried at room temperature. Finally, the stained smears were examined using immersion oil to detect oocysts of Cryptosporidium. In this method, Cryptosporidium oocysts appear as pink to red, spherical to ovoid bodies on a blue background. A stool was labeled as positive if the size of the oocysts ranged between $4 \mu \mathrm{m}$ and $6 \mu \mathrm{m}$.

\section{Quality control}

Fieldworkers were specifically trained under the guidance of a unified protocol prior to the field investigation. Two slides were prepared for each sample, and were examined by two separate laboratory technicians from the Center for Tropical Disease Research, Fudan University. The laboratory staff was not informed about the health status of the study participants to minimize observer bias. A third senior technician was summoned if there was disagreement concerning the results. All smears were stored in boxes at room temperature, and $10 \%$ of the examined slides were randomly selected and reexamined for quality control. All data were checked for accuracy.

\section{Data analysis}

Data were double entered and crosschecked with EpiData software (version 3.1; The EpiData Association, Odense, Denmark). Descriptive summary measures of frequency and central tendency of participants' characteristics were computed as appropriate. Pearson's chi-square test was employed in the univariable analysis to examine the associations between participants' characteristics and infection with HBV, HIV, and Cryptosporidium by computing crude odds ratios (cORs) with 95\% confidence intervals $(\mathrm{CIs})$. Multivariable logistic regression was subsequently carried out through stepwise elimination to adjust for confounders, and adjusted ORs (aORs) with $95 \% \mathrm{CIs}$ were calculated. $P \leq 0.05$ were considered statistically significant. Statistical analyses were done with the SPSS statistical package (version 20.0; IBM SPSS Institute, Inc., USA).

\section{Ethics statement}

The study was approved by the Ethics Review Committee of the Ethical Institute of the School of Public Health, Fudan University. Community leaders and local health authorities were informed during sensitization meetings about the purpose, procedures, potential risk, discomforts, and benefits of the study prior to the survey and sample collection.

All participants provided consent and were informed of their right to refuse to participate or withdraw at any point during the study. Written informed consent was obtained from the parents/guardians of children prior to study procedures after they had been clearly informed about the study. Participants infected with Cryptosporidium or with other medical conditions received appropriate treatment/ referral according to the local treatment policies and national guidelines. Identity and information collected were kept confidential.

\section{Results}

A total of 687 individuals were investigated in the study. Of them, 615 participants provided both blood and stool specimens, and were included in the analysis. There were no significant differences between participants included and those excluded in terms of gender, age, ethnicity, education, and annual family income.

The sociodemographic characteristics of the participants are summarized in Table 1. Participants were predominantly Yi people (99.8\%), of whom 251 (40.8\%) were male and more than half were married (62.3\%). The majority of the participants were illiterate $(62.1 \%)$ and farmers $(80.0 \%)$. The median age of the study participants was 34 years with an interquartile range from 14 
Table 1 Characteristics of the study population

\begin{tabular}{lll}
\hline Variables & No. of participants & $\%$ \\
\hline Total & 615 & 100.0 \\
Village & & \\
A & 172 & 28.0 \\
B & 158 & 25.7 \\
C & 129 & 21.0 \\
D & 156 & 25.4 \\
Gender & & \\
Male & 251 & 40.8 \\
Female & 364 & 59.2 \\
Age (years) & & $34(14,47)^{\mathrm{a}}$ \\
$0-10$ & 110 & 17.9 \\
$11-20$ & 75 & 12.2 \\
$21-30$ & 87 & 14.1 \\
$31-40$ & 118 & 19.2 \\
$41-50$ & 110 & 17.9 \\
$51-60$ & 64 & 10.4 \\
$>60$ & 51 & 8.3
\end{tabular}

Ethnicity

$\begin{array}{ll}\text { Yi } & 6 \\ \text { Han } & 1\end{array}$

Marital status

Not married

Married

Widowed

Body mass index $\left(B M l, \mathrm{~kg} / \mathrm{m}^{2}\right)$

$>18$
$\leq 18$

Education

|lliterate

Primary school

Middle school and above

Occupation

Student

Farmer

Other

Annual family income (yuan)

$\begin{array}{lll}<3000 & 117 & 19.0 \\ 3000-5000 & 188 & 30.6 \\ 5000-10000 & 116 & 18.9 \\ >10000 & 194 & 31.5\end{array}$

Keeping livestock or poultry (e.g., cattle, sheep, chicken)

$\begin{array}{lll}\text { No } & 155 & 25.2 \\ \text { Yes } & 460 & 74.8\end{array}$

Table 1 Characteristics of the study population (Continued)

Drinking unboiled water

$\begin{array}{lll}\text { No } & 14 & 2.3\end{array}$

$\begin{array}{lll}\text { Yes } & 589 & 97.7\end{array}$

Washing hands before meals

Often or always $\quad 352 \quad 58.2$

Never or occasionally $\quad 253 \quad 41.8$

Washing hands after defecation

$\begin{array}{lll}\text { Often or always } & 329 & 54.3 \\ \text { Never or occasionally } & 277 & 45.7\end{array}$

Washing fruits and raw vegetables before eating them

$\begin{array}{lcc}\text { Often or always } & 183 & 31.8 \\ \text { Never or occasionally } & 392 & 68.2 \\ \text { Having a household lavatory } & & \\ \text { No } & 239 & 40.4 \\ \text { Yes } & 352 & 59.6\end{array}$

Living under the same roof with livestock

$\begin{array}{lll}\text { No } & 541 & 93.9 \\ \text { Yes } & 35 & 6.1\end{array}$

Values are median (interquartile range)

to 47 years. The majority of the residents $(97.7 \%, 589 / 603)$ drank unboiled water, two-thirds $(68.2 \%, 392 / 575)$ never or occasionally washed fruits or vegetables, almost half hardly or occasionally washed their hands before meals or after defecation, and $40.4 \%$ (239/591) had no access to a household lavatory.

The prevalences of HIV, HBV, and Cryptosporidium were $2.30 \%, 8.30 \%$, and $12.0 \%$, respectively (see Table 2 ). The prevalences of HIV/HBV, HIV/Cryptosporidium, and HBV/Cryptosporidium co-infections were $0.3 \%, 0.3 \%$, and $1.8 \%$, respectively. Prevalence of Cryptosporidium was highest among individuals aged $41-50$ years, followed by elderly adults aged $\geq 60$ years and children aged $0-10$ years (see Table 4). No study participants had a multiple infection involving HBV, HIV, and Cryptosporidium. Results in Table 3 show that the prevalence of HBV

Table 2 Prevalence of infections and co-infections of HBV, HIV, and Cryptosporidium

\begin{tabular}{lll}
\hline & No. of infected participants & Infection rate \\
\hline HIV & 14 & 2.3 \\
HBV & 51 & 8.3 \\
Cryptosporidium & 74 & 12.0 \\
Co-infection & & \\
HIV and HBV & 2 & 0.3 \\
HIV and Cryptosporidium & 2 & 0.3 \\
HBV and Cryptosporidium & 11 & 1.8 \\
\hline
\end{tabular}


Table 3 Crude association between HBV infection and Cryptosporidium infection

\begin{tabular}{lllllll}
\hline \multirow{2}{*}{ Cryptosporidium infection } & \multicolumn{2}{l}{ HBV infection $\left[n(\%)^{\mathrm{a}}\right]$} & & $X^{2}$ & $P$ \\
\cline { 2 - 3 } & Yes & No & Total & & \\
\hline Yes & $11(15.1)$ & $62(84.9)$ & 73 & 5.00 & 0.03 \\
No & $40(7.4)$ & $502(92.6)$ & 542 & & \\
\hline
\end{tabular}

${ }^{\text {aPercentage in group }}$

infection was higher in individuals with Cryptosporidium infection $\left(\chi^{2}=5.00, P=0.03\right)$.

The results of the univariable and multivariable analyses for risk factors associated with Cryptosporidium infection are summarized in Table 4. The significant risk factors for acquiring Cryptosporidium infection were village of residence, keeping livestock or poultry, and being infected with HBV. After adjusting for covariates, an OR of 2.27 (95\% CI: 1.01-5.08, $P<0.05$ ) was associated with keeping livestock or poultry, and 3.42 (95\% CI: 1.47-7.92, $P<0.01)$ with HBV infection. HIV infection was not found to be significantly associated with Cryptosporidium infection $(\mathrm{aOR}=0.57,95 \% \mathrm{CI}$ : 0.07-4.39, $P=0.59$ ). No significant associations were observed between Cryptosporidium infection any hygiene habits including drinking unboiled water, eating raw food, washing hands before meals or after defecation, and owning a household lavatory.

\section{Discussion}

The study area had a very high prevalence of Cryptosporidium infection (12.0\%), according to modified acidfast staining. The prevalence of Cryptosporidium infection was much higher than the previously estimated range of $0.79-10.40 \%$ among either individuals without diarrhea or patients with diarrhea in other parts of China $[7,9,13]$. In particular, our data showed that the prevalence was highest among participants aged 41-50 years, followed by children aged $0-10$ years and elderly adults aged $\geq 60$ years, which was similar to results of other studies $[14,15]$. The high burden of Cryptosporidium infection may be attributed to poor personal hygiene and lack of sanitation facilities. The participants were predominantly Yi people with similar occupations, cultural traditions, and living conditions. For instance, only $2.3 \%$ of the participants would boil water before drinking it and nearly half of them had no access to a household lavatory. Not using sanitation facilities and water treatment and poor hygiene habits of some of the participants might increase the general environmental contamination and thereby increases the risk of Cryptosporidium infection for all other persons living in the same setting [16]. Therefore, the protective effects of sanitation and hygiene habits could have been underestimated. Moreover, owing to its low latitude and high elevation, the town studied has a mild climate and belongs to the humid subtropical zone. A recent metaanalysis examining the effects of seasonality showed that increases in both temperature and rainfall were associated with an increased risk of cryptosporidiosis [17]. These local climatic conditions define a typical habitat area for Cryptosporidium species. Alternatively, these differences may reflect the use of different diagnostic techniques. In addition, we found that participants who raised livestock or poultry were more likely to be infected with Cryptosporidium, which was consistent with previous studies conducted elsewhere [18-21].

The prevalence of HBV infection observed in our study corroborated previous nationwide large-scale epidemiological studies [22]. The majority of individuals found to be HBV-positive had not received appropriate treatment for HBV infection given they were diagnosed for the first time. Therefore, screening and diagnosis of HBV are of great importance for reducing the risk of HBV transmission and subsequent HBV-related diseases. Intriguingly, we found that HBV infection and Cryptosporidium infection were significantly associated with each other. For chronic hepatitis B, long-lasting virus persistence is related to a lack of memory T-cell maturation and severely impaired T-cell function, followed by a suppressed production of primary cytokines [23-25], which may increase the susceptibility to Cryptosporidium infection. A recent study demonstrated that the infection rate of Cryptosporidium spp. was higher in chronic hepatitis B patients than in healthy controls [26]. On the other hand, Cryptosporidium infection leads to an imbalance between Th1 and Th2 cytokines, along with inflammatory damage to the host's small intestine $[3,27]$, which may facilitate the occurrence of HBV infection. Further research is required to explore the host immune responses to coinfection with HBV and Cryptosporidium. Such investigations would help interpret this finding and explore the clinical significance of cryptosporidiosis in patients infected with HBV.

The prevalence of HIV infection was 2.3\%, which was much higher than the provincial and national levels, $0.170 \%$ and $0.058 \%$, respectively $[28,29]$. The vast majority of the participants were Yi people, who live in one of the poorest areas in China. Previous studies have shown that poverty is associated with HIV infection [30, 31]. Additionally, the local custom requests a man to marry his brother's widow in order to maintain the family lineage, even if his brother have died of HIV-related illnesses or his sister-in-law has been diagnosed as HIV infection. Casual sex without condom also facilitates the spreading of HIV [32]. The prevalence of Cryptosporidium infection was $7.1 \%(1 / 14)$ in patients infected with HIV, which was in agreement with observations elsewhere $[8,33]$. There was no significant association found 
Table 4 Univariable and multivariable analyses for risk factors associated with Cryptosporidium infection

\begin{tabular}{|c|c|c|c|c|c|c|}
\hline Variables & No. of participants & Infection rate (\%) & COR $(95 \% \mathrm{Cl})$ & $P$ & $\mathrm{aOR}(95 \% \mathrm{Cl})$ & $P$ \\
\hline \multicolumn{7}{|l|}{ Village } \\
\hline A & 172 & 16.3 & 1.00 & 0.02 & 1.00 & 0.02 \\
\hline B & 158 & 14.6 & $0.88(0.48-1.60)$ & 0.67 & $0.81(0.39-1.70)$ & 0.58 \\
\hline C & 129 & 10.1 & $0.58(0.29-1.16)$ & 0.12 & $0.47(0.21-1.08)$ & 0.08 \\
\hline D & 156 & 5.8 & $0.32(0.14-0.69)$ & $<0.01$ & $0.26(0.10-0.64)$ & $<0.01$ \\
\hline \multicolumn{7}{|l|}{ Gender } \\
\hline Male & 251 & 13.5 & 1.00 & & & \\
\hline Female & 364 & 10.7 & $0.77(0.47-1.25)$ & 0.29 & & \\
\hline \multicolumn{7}{|l|}{ Age (years) } \\
\hline $0-10$ & 110 & 12.7 & 1.00 & 0.24 & & \\
\hline $11-20$ & 75 & 6.7 & $0.49(0.17-1.42)$ & 0.19 & & \\
\hline $21-30$ & 87 & 10.3 & $0.79(0.33-1.93)$ & 0.61 & & \\
\hline $31-40$ & 118 & 8.5 & $0.64(0.27-1.50)$ & 0.30 & & \\
\hline $41-50$ & 110 & 17.3 & $1.43(0.68-3.02)$ & 0.35 & & \\
\hline $51-60$ & 64 & 10.9 & $0.84(0.32-2.21)$ & 0.73 & & \\
\hline$>60$ & 51 & 17.6 & $1.47(0.59-3.66)$ & 0.41 & & \\
\hline \multicolumn{7}{|l|}{ Marital status } \\
\hline Not married & 194 & 11.3 & 1.00 & 0.74 & & \\
\hline Married & 383 & 11.7 & $1.04(0.61-1.79)$ & 0.89 & & \\
\hline Widowed & 38 & 15.8 & $1.47(0.55-3.90)$ & 0.44 & & \\
\hline \multicolumn{7}{|l|}{ Body mass index (BMl, kg/m²) } \\
\hline$>18$ & 526 & 12.2 & 1.00 & & & \\
\hline$\leq 18$ & 89 & 10.1 & $0.81(0.39-1.70)$ & 0.58 & & \\
\hline \multicolumn{7}{|l|}{ Education level } \\
\hline No school & 382 & 12.0 & 1.00 & 0.85 & & \\
\hline Primary school & 206 & 11.2 & $0.92(0.54-1.56)$ & 0.75 & & \\
\hline Middle school and above & 27 & 14.8 & $1.27(0.42-3.84)$ & 0.67 & & \\
\hline \multicolumn{7}{|l|}{ Occupation } \\
\hline Student & 113 & 9.7 & 1.00 & 0.72 & & \\
\hline Farmer & 492 & 12.4 & $0.76(0.39-1.50)$ & 0.43 & & \\
\hline Other & 10 & 10.0 & $0.79(0.10-6.31)$ & 0.82 & & \\
\hline \multicolumn{7}{|l|}{ Annual family income(yuan) } \\
\hline$<3000$ & 117 & 10.3 & 1.00 & 0.63 & & \\
\hline $3000-5000$ & 188 & 12.8 & $1.28(0.61-2.67)$ & 0.51 & & \\
\hline $5000-10000$ & 116 & 14.7 & $1.50(0.68-3.31)$ & 0.31 & & \\
\hline$>10000$ & 194 & 10.3 & $1.01(0.47-2.14)$ & 1.00 & & \\
\hline \multicolumn{7}{|c|}{ Keeping livestock or poultry (e.g., cattle, sheep, chicken) } \\
\hline No & 155 & 7.1 & 1.00 & & 1.00 & \\
\hline Yes & 460 & 13.5 & $2.04(1.05-3.98)$ & 0.04 & $2.27(1.01-5.08)$ & $<0.05$ \\
\hline \multicolumn{7}{|l|}{ Drinking unboiled water } \\
\hline No & 14 & 14.3 & 1.00 & & & \\
\hline Yes & 589 & 12.1 & $0.82(0.18-3.75)$ & 0.80 & & \\
\hline
\end{tabular}


Table 4 Univariable and multivariable analyses for risk factors associated with Cryptosporidium infection (Continued)

\begin{tabular}{|c|c|c|c|c|c|c|}
\hline \multicolumn{7}{|c|}{ Washing hands before meals } \\
\hline Often or always & 352 & 12.2 & 1.00 & & & \\
\hline Never or occasionally & 253 & 11.9 & $0.97(0.59-1.59)$ & 0.89 & & \\
\hline \multicolumn{7}{|c|}{ Washing hands before defecation } \\
\hline Often or always & 329 & 12.5 & 1.00 & & & \\
\hline Never or occasionally & 277 & 11.6 & $0.92(0.56-1.50)$ & 0.73 & & \\
\hline \multicolumn{7}{|c|}{ Washing fruits and raw vegetables before eating them } \\
\hline Often or always & 183 & 13.3 & 1.00 & & & \\
\hline Never or occasionally & 392 & 10.4 & $0.76(0.43-1.32)$ & 0.33 & & \\
\hline \multicolumn{7}{|c|}{ Having a household lavatory } \\
\hline No & 239 & 12.6 & 1.00 & & & \\
\hline Yes & 352 & 11.9 & $0.94(0.57-1.56)$ & 0.82 & & \\
\hline \multicolumn{7}{|c|}{ Living under the same roof with livestock } \\
\hline No & 541 & 12.6 & 1.00 & & & \\
\hline Yes & 35 & 8.6 & $0.65(0.19-2.19)$ & 0.50 & & \\
\hline \multicolumn{7}{|l|}{ HIV infection } \\
\hline No & 601 & 12.0 & 1.000 & & & \\
\hline Yes & 14 & 7.1 & $0.57(0.07-4.39)$ & 0.59 & & \\
\hline \multicolumn{7}{|l|}{ HBV infection } \\
\hline No & 564 & 11.0 & 1.00 & & 1.00 & \\
\hline Yes & 51 & 21.6 & $2.23(1.09-4.56)$ & 0.03 & $3.42(1.47-7.92)$ & $<0.01$ \\
\hline
\end{tabular}

between HIV infection and Cryptosporidium infection in our study. An earlier survey found a higher prevalence of Cryptosporidium among AIDS patients who refused antiretroviral therapy (ART) $(21.21 \%$; $7 / 33)$ than those who accepted regular treatment $(4.25 \% ; 9 / 212)$ [8]. The number of people with HIV infection was small in this study. Another reason may be that these HIV-positive individuals were not immunocompromised yet because the majority of the HIV-infected individuals were diagnosed for the first time and were at the early stage of the disease. As a result, they received no ART or were rarely treated. Along with the development of HIV infection and weakening of immunity, cryptosporidiosis in patients with HIV infection could be a major public health issue given the lack of an effective specific therapy or vaccine. Therefore, local governments and CDCs need to make more efforts in expanding access to and coverage of ART for patients with HIV infection.

There are some limitations to this study. Firstly, only one stool sample was collected from each participant. Given the intermittent shedding pattern of Cryptosporidium oocysts, the examination based on a single sample may lead to an underestimated prevalence of Cryptosporidium infection. Secondly, males were underrepresented because many young males in rural areas drift to the cities for better work opportunities. Additionally, our study used modified acid-fast staining to detect the existence of
Cryptosporidium oocysts. However, misclassification may occur because the sensitivity and specificity of this method are not high [1]. To minimize the risk of misclassification, each smear was read by two separate technicians without knowing the study participant's identity. One-tenth of the examined slides were randomly selected and re-examined for quality control. Moreover, it should be noted that the modified acid-fast staining employed in our study does not discriminate between Cryptosporidium species and subtypes, without which it is impossible to determine the infectious source of Cryptosporidium in this setting. Genotyping and subtyping tools have been used increasingly in the characterization of the transmission of Cryptosporidium [34-36]. Further research could include molecular analysis in order to determine the roles of anthroponotic and zoonotic transmission of Cryptosporidium in rural China. In view of these limitations, the findings of this study should be interpreted with caution when being generalized to the larger population and compared with results from other studies.

\section{Conclusions}

In conclusion, there was a high prevalence of Cryptosporidium infection among residents in the community under investigation. An association was found between HBV infection and Cryptosporidium infection. Since no effective specific therapeutic agent for cryptosporidiosis 
is available at present, fenced husbandry, health education, and environmental sanitation programs might help reduce the occurrence of Cryptosporidium infections, and so could hepatitis B vaccination as well as timely ART for patients with HIV. Further research is required to determine the clinical significance of this parasite in individuals infected with $\mathrm{HBV}$, and the interaction between HBV and Cryptosporidium.

\section{Additional file}

Additional file 1: Multilingual abstracts in the five official working languages of the United Nations. (PDF $702 \mathrm{~kb}$ )

\section{Abbreviations}

AIDS: Acquired immune deficiency syndrome; aOR: Adjusted odds ratio; ART: Antiretroviral therapy; CDC: Center for Disease Control and Prevention; Cl: Confidence interval; COR: Crude odds ratio; HBV: Hepatitis B virus; HIV: Human immunodeficiency virus; OR: Odds ratio

\section{Acknowledgements}

We would like to thank the technical staff of the local CDC for their invaluable work, and the local government officials for their support in data and sample collection.

\section{Funding}

This research received no specific grant from any funding agency, commercial or not-for-profit sectors.

\section{Availability of data and materials}

The data of this paper are part of a large data set and are available in the Center for Tropical Disease Research, Fudan University. Therefore, access to these data should be gained by contacting the corresponding author directly

\section{Authors' contributions}

$Y Y, Y-B Z, X-X S$, and Q-WJ conceived and designed the experiments. YY, Y-BZ, $P-L X, Y S, W-L Y$, and $X-X S$ performed the fieldwork. $Y Y, Y-B Z, Y C, S L, X-X S$, and $\mathrm{Q}-\mathrm{WJ}$ contributed to the data analysis and wrote the paper. All authors read and approved the final paper.

\section{Competing interests}

The authors declare that they have no competing interests.

\section{Ethics approval and consent to participate}

The study was approved by the Ethics Review Committee of the Ethical Institute of the School of Public Health, Fudan University. All participants provided consent and were informed of their right to refuse to participate or withdraw at any point during the study.

\section{Author details}

'School of Public Health, Fudan University, Building 8, 130 Dong'an Road, Xuhui District, Shanghai 200032, China. ${ }^{2}$ Key Laboratory of Public Health Safety, Fudan University, Ministry of Education, Building 8, 130 Dong'an Road, Xuhui District, Shanghai 200032, China. ${ }^{3}$ Center for Tropical Disease Research, Fudan University, Building 8, 130 Dong'an Road, Xuhui District, Shanghai 200032, China. ${ }^{4}$ School of Epidemiology, Public Health and Preventive Medicine, Faculty of Medicine, University of Ottawa, 451 Smyth Road, Ottawa, ON K1H 8M5, Canada. ${ }^{5}$ Department of Environmental and Global Health, College of Public Health and Health Professions, University of Florida, 2055 Mowry Road, Gainesville, FL 32611, USA. ${ }^{6}$ Emerging Pathogens Institute, University of Florida, 2055 Mowry Road, Gainesville, FL 32611, USA. ${ }^{7}$ Puge Center for Disease Prevention and Control, 6 Qingnian Road, Puge County, Sichuan 615300, China.

Received: 11 January 2016 Accepted: 15 December 2016 Published online: 09 January 2017

\section{References}

1. Checkley W, White AC, Jaganath D, Arrowood MJ, Chalmers RM, Chen X, et al. A review of the global burden, novel diagnostics, therapeutics, and vaccine targets for cryptosporidium. Lancet Infect Dis. 2015;15:85-94.

2. Kotloff KL, Nataro JP, Blackwelder WC, Nasrin D, Farag TH, Panchalingam S, et al. Burden and aetiology of diarrhoeal disease in infants and young children in developing countries (the Global Enteric Multicenter Study, GEMS): a prospective, case-control study. Lancet. 2013;382:209-22.

3. O'Connor RM, Shaffie R, Kang G, Ward HD. Cryptosporidiosis in patients with HIV/AIDS. AIDS. 2011;25:549-60.

4. Savioli L, Smith $H$, Thompson A. Giardia and cryptosporidium join the 'neglected diseases initiative'. Trends Parasitol. 2006;22:203-8.

5. Ferrari C. HBV and the immune response. Liver Int. 2015;35 Suppl 1:121-8.

6. Han F, Tan W, Zhou X. Two case reports of cryptosporidiosis in Nanjing. Jiangsu Med J. 1987:12:692.

7. Lv S, Tian L, Liu Q, Qian M, Fu Q, Steinmann P, et al. Water-related parasitic diseases in China. Int J Env Res Pub He. 2013:10:1977-2016.

8. Yue XH, Wang H, Gou JZ, Chen XC, Yang GL, Yang QT, et al. Detection of Cryptosporidium infection in AIDS patients in Guangdong and Yunnan. Chin J Exp Clin Virol. 2008;22:339-41.

9. Fan $B$, He XY, Huang ZM, Wang WL, Bo WF, Su Q. Epidemiological investigation of cryptosporidiosis in Yuxi district. Chin J Pest Contr. 1992:4:228-30.

10. UNAIDS. China AIDS Response Progress Report. Available at: http://unaids. org.cn/uploadFiles/2015060516205863.pdf. Accessed 15 Oct 2015.

11. Li K, Wu G, Xu H, Zou K. Prevalence of HBV in a mountainous area. Modern Preventive Med. 2007;34:2557-8.

12. Yihuo WL, Zhou YB, Liu GM, Wu ZS, Wang SA, Xu L, et al. Effect of four-year comprehensive schistosomiasis control in Puge County, Sichuan Province. Chin J Schisto Control. 2009:21:276-9.

13. Zhu M, Zhu J, Wang S, Song M. A survey of Cryptosporidium infection among humans being in Shiyan, China. J Path Biol. 2009:04:685-6.

14. Painter JE, Hlavsa MC, Collier SA, Xiao L, Yoder JS. Cryptosporidiosis surveillance-United States, 2011-2012. MMWR Surveillance Summaries. 2015;64:1-14.

15. Laupland KB, Church DL. Population-based laboratory surveillance for Giardia sp. and Cryptosporidium sp. infections in a large Canadian health region. BMC Infect Dis. 2005:5:72.

16. Speich B, Croll D, Furst T, Utzinger J, Keiser J. Effect of sanitation and water treatment on intestinal protozoa infection: a systematic review and meta-analysis. Lancet Infect Dis. 2016;16:87-99.

17. Jagai JS, Castronovo DA, Monchak J, Naumova EN. Seasonality of cryptosporidiosis: A meta-analysis approach. Environ Res. 2009;109:465-78.

18. Robertson B, Sinclair MI, Forbes AB, Veitch M, Kirk M, Cunliffe D, et al. Case-control studies of sporadic cryptosporidiosis in Melbourne and Adelaide, Australia. Epidemiol Infect. 2002;128:419-31.

19. Smith KE, Stenzel SA, Bender JB, Wagstrom E, Soderlund D, Leano FT, et al, Outbreaks of enteric infections caused by multiple pathogens associated with calves at a farm day camp. Pediatr Infect Dis J. 2004:23:1098-104.

20. Lange $\mathrm{H}$, Johansen $\mathrm{OH}$, Vold L, Robertson L, Anthonisen IL, Nygard K Second outbreak of infection with a rare Cryptosporidium parvum genotype in schoolchildren associated with contact with lambs/goat kids at a holiday farm in Norway. Epidemiol Infect. 2014:142:2105-13.

21. Hunter PR, Hughes S, Woodhouse S, Syed Q, Verlander NQ, Chalmers RM, et al. Sporadic cryptosporidiosis case-control study with genotyping. Emerg Infect Dis. 2004;10:1241-9.

22. Wang F, Fan J, Zhang Z, Gao B, Wang H. The global burden of liver disease: The major impact of China. Hepatology. 2014;60:2099-108.

23. Balmasova IP. Immunopathogenesis of chronic hepatitis B. World J Gastroenterol. 2014;20:14156-71.

24. Wherry EJ, Ahmed R. Memory CD8 T-cell differentiation during viral infection. J Virol. 2004:78:5535-45.

25. Guan SH, Lu M, Grunewald P, Roggendorf M, Gerken G, Schlaak JF. Interferonalpha response in chronic hepatitis B-transfected HepG2.2.15 cells is partially restored by lamivudine treatment. World J Gastroenterol. 2007;13:228-35.

26. Li F, Zhang $X$, Wu Q, Chen W. Prevalence of Cryptosporidium infection in patients with chronic hepatitis B. New Med. 2007;38:81-3.

27. McDonald SA, O'Grady JE, Bajaj-Elliott M, Notley CA, Alexander J, Brombacher $F$, et al. Protection against the early acute phase of Cryptosporidium parvum infection conferred by interleukin-4-induced expression of T helper 1 cytokines. J Infect Dis. 2004;190:1019-25. 
28. Liang L, Liu L, Fei X, Luo Y, Hu Y. Detection on HIV in Sichuan Province, 2008-1011. J Prev Med Inf. 2013;29:453-6.

29. Dong C, Huang Z, Martin MC, Huang J, Liu H, Deng B, et al. The impact of social factors on human immunodeficiency virus and hepatitis $\mathrm{C}$ virus co-infection in a minority region of Si-chuan, the People's Republic of China: a population-based survey and testing study. PLoS One. 2014;9:e101241.

30. Zhou Y, Wang Q, Liang S, Gong Y, Yang M, Chen Y, et al. Geographical variations in risk factors associated with HIV infection among drug users in a prefecture in Southwest China. Infect Dis Poverty. 2015;4:38. doi:10.1186/ s40249-015-0073-x.

31. Masanjala W. The poverty-HIV/AIDS nexus in Africa: A livelihood approach. Soc Sci Med. 2007;64:1032-41.

32. Yang Y, Luan RS, Liu P, Wu CL, Zhou Y, Chen W. Casual sex and concurrent sexual partnerships among young people from an $\mathrm{Yi}_{\mathrm{i}}$ community with a high prevalence of HIV in China. Asian J Androl. 2012;14:758-65.

33. Tian LG, Chen JX, Wang TP, Cheng GJ, Steinmann P, Wang FF, et al. Co-infection of HIV and intestinal parasites in rural area of China. Parasit Vectors. 2012;5:36.

34. Wang L, Zhang H, Zhao X, Zhang L, Zhang G, Guo M, et al. Zoonotic cryptosporidium species and enterocytozoon bieneusi Genotypes in HIVpositive patients on antiretroviral therapy. J Clin Microbiol. 2013;51:557-63.

35. Feng $Y$, Wang $L$, Duan $L$, Gomez-Puerta $L A$, Zhang $L$, Zhao X, et al. Extended outbreak of cryptosporidiosis in a Pediatric Hospital, China. Emerg Infect Dis. 2012;18:312-4.

36. Wang R, Zhang $X$, Zhu H, Zhang L, Feng Y, Jian F, et al. Genetic characterizations of Cryptosporidium spp. and Giardia duodenalis in humans in Henan, China. Exp Parasitol. 2011;127:42-5.

\section{Submit your next manuscript to BioMed Central and we will help you at every step:}

- We accept pre-submission inquiries

- Our selector tool helps you to find the most relevant journal

- We provide round the clock customer support

- Convenient online submission

- Thorough peer review

- Inclusion in PubMed and all major indexing services

- Maximum visibility for your research

Submit your manuscript at www.biomedcentral.com/submit 